\title{
Assessment of Risk Factors, Feasibility and Acceptability of VIA for Cervical Cancer Screening and Prevention
}

\author{
Rijal P, Pradhan T, Agrawal A, Rai R, Bhatta R, Chhetri S \\ ${ }^{1}$ Dept of obs/gyane, BPKIHS, Dharan, Nepal
}

Received: December 22, 2015 ; Accepted: February 2, 2016

\begin{abstract}
Aims: To assess feasibility of visual inspection with acetic acid and treatment with cryotherapy for cervical cancer screening and prevention and assess risk factors for cervical cancer in the screened population.
\end{abstract}

Methods: A prospective analysis of all patients enrolled for cervical cancer screening by visual inspection, meeting the eligibility criteria for screening and treatment as per national guidelines 2011 was analyzed form March 2012 to April 2013.

Results: A total of 4138 met the eligibility criteria and were counseled for screening, 33 rejected for screening. Out of 4105 screened 241 were VIA positive, 211 were treated with cryotherapy, 25 treated with LEEP, 5 rejected to treatment. Mean age of patient in year's \pm SD $41.48 \pm 9.72$. The VIA positivity rate was $5.9 \%$

Conclusions: Single visit approach is a feasible and acceptable form of cervical cancer screening strategy in our population.

Keywords: cervical cancer, cryotherapy, SVA - single visit approach

\section{INTRODUCTION}

Cervical cancer is the third most common cancer in women and is considered a major health concern worldwide with more than $85 \%$ of the global burden of cervical cancer occurring in developing countries. The high-risk regions are Asia and Africa. In these regions the age standardized incidence rate is greater than 30 per 100,000 . In comparison, the age standardized incidence rate in North America and Australia/New Zealand is less than eight per 100,000. Cervical cancer is responsible for 275,000 deaths annually, about $88 \%$ of which occurs in developing countries. ${ }^{1}$ Lack of effective screening programs for cervical cancer explains high mortality in developing countries. As a consequence, no clinically significant reduction in the incidences of cervical cancer has occurred. ${ }^{2,3}$ In contrast, there has been a major decline in cervical cancer mortality in developed countries after the introduction of population-based screening programs based on Papanicolaou smears (Pap smears) to detect cervical abnormalities. ${ }^{4}$

A screening program based on Pap smears requires complex infrastructure which may be unavailable

\section{CORRESPONDENCE}

Dr Pappu Rijal

Associate professor

Dept of obs/gyane, BPKIHS, Dharan, Nepal

drrijal315@yahoo.com

9852022315 in most developing countries. Therefore there is a need for more simple screening methods which can be interpreted immediately and combined with treatment. Visual inspection of the cervix after acetic acid application (VIA) is believed to be an effective method for screening in resource-limited settings. ${ }^{5}$ VIA is performed by a trained health care provider who applies acetic acid solution to the cervix and then observes the transformation zone of the cervix for one to two minutes for acetowhite epithelium, which is thought to be indicative of abnormal cellular changes. ${ }^{6}$ The implementation of VIA as a screening strategy has shown promising results and screening programs based on this methodology are being implemented increasingly in low income countries. ${ }^{7,8}$

Nepal is a developing country in South Asia and the burden of this problem is also high .As per National Cancer Registry Programme, data collected from seven major hospitals of Nepal as of 2005 shows that cervical cancer accounts for $21.4 \%$ of all cancers in women and is the second most common cancer in women after lung cancer. With this high burden of cervical cancer the National Cervical Cancer Screening and Prevention Programme(NCCSP) was initiated by the government of Nepal in 2011 and VIA as the screening test and cryotherapy as the treatment of choice for positive lesions. The service was started in our department from 2012 March. 


\section{METHODS}

A prospective analysis was done after institutional ethical clearance. The objective was to analyze the feasibility of single Visit Approach (SVA) in which women were tested by Visual inspection with acetic acid (VIA) for cervical cancer screening and treatment with cryotherapy in case of positive test result and to asses risk factors for cervical cancer in the screened population .As per the NCCSP guidelines enrollment criteria for VIA were all women of 30-60 years as target age group but younger women if married earlier or sexually active were also enrolled.VIA testing was done in gynecology outpatient department using $5 \%$ acetic acid.

Women were initially counseled about the importance of cervical cancer screening and VIA testing, possible test results, post test follow up if found negative, possible treatment options in case of positive test result in the initial step and testing was done by VIA trained nurse or doctor. Negative were counseled to return in five years for retesting and positive were counseled for cryotherapy. A standard VIA form was used for individual client for data entry and record keeping by verbal questionnaire with the woman for data collection. The data was entered into excel sheet for analysis.

The presence or absence of risk factors like previous history of abnormal Pap test, smoking status, use of barrier contraception, family history of cervical cancer, post coital bleed were also recorded as per the VIA form. Eligibility criteria for cryotherapy was acetowhite lesion occupying less than $75 \%$ of cervix ,no vaginal extension, maximum extension of lesion less than two millimeters beyond cryo tip . Double freeze technique for cryotherapy was used. Women ineligible for cryotherapy were treated by loop electro excision (LEEP) procedure. After treatment clients were followed up at three and six months and retested by VIA at one year. If found negative clients were asked to follow up after five years or re-treatment was done by cryotherapy / LEEP in case of repeat positive.

\section{RESULTS}

Data were entered into excel sheet and analyzed by SPSS ver. 11. During the study period from March 2012 to April 2013 a total of 4138 cases were counseled for screening and 33 rejected for testing, so 4105 were tested with VIA. Of the tested sample 241 were found to be positive out of which five of them rejected to any form of treatment, 211 were treated with cryotherapy and 25 were treated with LEEP. Demographic parameters revealed mean age of patient in year's \pm SD $41.48 \pm 9.72$, mean age at marriage in year's \pm SD $21.83 \pm 3.14$ and median age of parity inter quartile range 3(2-3) (Table 1). Analysis of presence of risk factors in the population revealed a low prevalence of risk factors in the population except for a presence of recurrent pelvic infection which was present in $14 \%$ of the study population. (Table 2). The VIA positivity rate was 5.9\%.During screening five cases of invasive cervical cancer of advanced stage were detected which were referred for radiotherapy after histological confirmation and were not included in the analysis .

Table 1. Demographic parameters of the study population $(\mathrm{n}=4105)$

\begin{tabular}{|c|c|c|c|}
\hline Risk factors & Categories & $\begin{array}{l}\text { No of } \\
\text { Patients }\end{array}$ & $\begin{array}{l}\text { Percentage } \\
(\%)\end{array}$ \\
\hline \multirow[t]{4}{*}{ Age group (years) } & $<30$ & 434 & 10.6 \\
\hline & $31-40$ & 1635 & 39.8 \\
\hline & $41-50$ & 1229 & 29.9 \\
\hline & $51-60$ & 807 & 19.7 \\
\hline $\begin{array}{l}\text { Mean age of } \\
\text { patient (year's) }\end{array}$ & \multicolumn{3}{|c|}{$\pm \mathrm{SD} 41.48 \pm 9.72$} \\
\hline \multirow{2}{*}{$\begin{array}{l}\text { Age at marriage } \\
\text { (year's) }\end{array}$} & $<20$ & 757 & 18.4 \\
\hline & $\geq 20$ & 3348 & 81.6 \\
\hline $\begin{array}{l}\text { Mean age at } \\
\text { marriage (year's) }\end{array}$ & \multicolumn{3}{|c|}{$\pm \mathrm{SD} 21.83 \pm 3.14$} \\
\hline \multirow[t]{6}{*}{ Parity } & Nullipara & 145 & 3.5 \\
\hline & 1 & 391 & 9.5 \\
\hline & 2 & 1203 & 29.3 \\
\hline & 3 & 1750 & 42.6 \\
\hline & 4 & 235 & 5.7 \\
\hline & $\geq 5$ & 381 & 9.3 \\
\hline $\begin{array}{l}\text { Median parity } \\
\text { of patient (IQR) }\end{array}$ & $3(2-3)$ & & \\
\hline
\end{tabular}

Table 2. Risk factors for cervical cancer in the study population $(n=4105)$

\begin{tabular}{|llll|}
\hline Risk factors & absent & present (\%) \\
\hline Contraceptive use (barrier) & 3673 & $432(10.5)$ \\
History of post coital bleed & 4006 & $99(2.4)$ \\
Smoker & 3796 & $309(7.5)$ \\
Family history of cervical cancer & 3783 & $322(7.8)$ \\
Recurrent pelvic infection & 3512 & $593(14.4)$ \\
Previous abnormal PAP smears & 4090 & 15 & $(0.4)$ \\
\hline
\end{tabular}

Among those treated with cryotherapy 15 patients returned in less than six weeks with complaints of excess vaginal discharge but after examination it was found to be normal and they didn't require any further treatment. Among those 25 treated with LEEP, 
five patients returned in less than six weeks with complaints of vaginal bleeding and they were treated with oral tranexamic acid. Among 25 patients treated with LEEP, 23 patients had histopathological report of CIN1/2 and two had report of CIN3 on whom hysterectomy was performed on patients request after discussing the risks and benefits of conservative treatment.

The patients were assessed during follow up at three months, six months and one year and repeat VIA was done at the end of one year. Of the 236 treated for VIA positive only 202 came for follow up after one year (21 LEEP group and 181 cryotherapy group). In the cryotherapy group repeat VIA was positive in five out of $181(2.7 \%)$, who were advised for repeat treatment with LEEP and four were treated with LEEP and one opted for hysterectomy and was performed . In the LEEP group only one out of 21 tested positive and the patient refused conservative treatment again and hysterectomy was performed.

\section{DISCUSSION}

Various studies have been conducted around the globe to estimate the feasibility and acceptability of SVA for cervical cancer screening and treatment .In the present study only 33 out of those 4138 rejected for screening with VIA, which shows high acceptance similar to other series reported. ${ }^{8,9,10}$ The VIA positivity rate in the current series is $5.9 \%$ which is similar to other series reported ${ }^{11,12,17}$ but higher percentage reported in other series were done in a cohort of high risk groups comprising of HIV positive population or HPV - DNA positive population. ${ }^{7,12}$

Our population displayed a significantly low prevalence of risk factors like presence of HIV or previous abnormal Pap Smears which could be explained by the fact of low prevalence of HIV in general population and very low voluntary cervical cancer screening practices in our population. Studies focused on screening on high risk groups and adoption of HPV DNA testing in our screening programmes will help estimate the actual presence of risk factors in our population.

A small percentage of patients who received treatment lost to follow up at the end of one year, which could be due to financial constraints, difficult in access to health services as pointed out in a similar study.$^{13}$ Presence of severe side effects with either form of treatment have been reported in a very few series except minor complaints of vaginal discharge or vaginal spotting which is expected to be normal after these treatment procedures.

A more organized screening system should be initiated to keep track of all those who has received treatment or not received any form of treatment. During follow up at the end of one year, $2.7 \%$ of those who received cryotherapy as initial treatment were found to be repeat positive, which is more or less similar to the series reported. ${ }^{14,15,16}$ A more detailed evaluation using a bigger sample size is required to estimate the true positivity rate in our population.

\section{CONCLUSION}

Screening with VIA and treatment with cryotherapy (SVA) has a high acceptance rate in our population with low side effects. In spite of high burden of clinically detected advanced stage cervical cancer the low prevalence of risk factor emphasizes the need to incorporate screening of high risk groups like HIV positive groups and HPV DNA testing in our screening programme. We should also focus on strategies to improve women's voluntary participation in screening programmes.

\section{REFERENCES}

1. Arbyn M, Castellsague X, de Sanjose S, Bruni L, Saraiya M, Bray F.et.al. Worldwide burden of cervical cancer in 2008. Ann Oncol. 2011; 22(12):2675-86.

2. Sankaranarayanan R, Budukh AM, Rajkumar R. Effective screening programmes for cervical cancer in low and middleincome developing countries. Bull World Health Organ.2001; 79(10):954-62.

3. CCA: Progress in Cervical Cancer Prevention: The CCA Report Card.: Cervical Cancer Action; 2012 [cited 2015 dec15] Availablefrom:http://www.cervicalcanceraction.org/ pubs/CCA reportcard low-res.pdf.

4. CDC: United States Cancer Statistics: 1999-2007 Incidence and Mortality Web-based Report. Atlanta: Department of

Health and Human Services; Centers for Disease Control and Prevention; National Cancer Institute; 2010.

5. Denny L, Kuhn L, Pollack A, Wright TC Jr. Direct visual inspection for cervical cancer screening: an analysis of factors influencing test performance. Cancer. 2002; 94(6):1699-07.

6. Sankaranarayanan R, Wesley RS. A practical manual on visual screening for cervical neoplasia. Lyon, France- International Agency for Research on Cancer Technical publication; 2003.

7. Ngoma T, Muwonge R, Mwaiselage J, Kawegere J, Bukori P,Sankaranarayanan R. Evaluation Of cervical visual inspection screening in Dar es Salaam, Tanzania. Int $\mathbf{J}$ Gynecol Obstet .2010; 109 (2):100-4. 
8. SankaranarayananR, RajkumarR, EsmyPO, FayetteJM, ShanthakumaryS, FrappartL.et.al. Effectiveness, safety and acceptability of 'see and treat' with cryotherapy by nurses in a cervical screening study in India. Br J Cancer. 2007; 96(5):738-43.

9. Adefuye PO, Dada OA, Adefuye BO. Feasibility, acceptability, and effectiveness of visual inspection of the cervix with acetic acid and cryotherapy for dysplasia in Nigeria. Int $\mathrm{J}$ Gynecol Obstet. 2015; 129(1):62-6.

10. Phongsavan K, Phengsavanh A, Wahlström R, Marions L. Safety, feasibility, and acceptability of visual inspection with acetic acid and immediate treatment with cryotherapy in rural Laos. Int J Gynecol Obstet. 2011; 114(3):268-72.

11. Blumenthal PD, Gaffikin L, Deganus S, Lewis R, Emerson M. Cervical cancer prevention: safety, acceptability, and feasibility of a single-visit approach in Accra, Ghana. Am J Obstet Gynecol. 2007;196(4):1-8.

12. Gaffikin L, Blumenthal PD, Emerson M. Safety, acceptability and feasibility of a single-visit approach to cervicalcancer prevention in rural Thailand: a demonstration project. Lancet. 2003; 361(9360):814-20.
13. Ngichabe SK, Muthaura PN, Murungi C, Muyoka J, Omenge E, Muchiri L Cryotherapy following VIA and Lugols iodine in Kkwasiro, western Kenya : lessons from field affecting policy and practice . East Afr Med J. 2013; 90(10):316-23

14. Chumworathayi B, Srisupundit S, Lumbiganon $\mathrm{P}$, Limpaphayom KK .One-year follow-up of single-visit approach to cervical cancer prevention based on visual inspection with acetic acid wash and immediate cryotherapy in rural Thailand. Int J Gynecol Cancer. 2008; 18(4):736-42

15. Blumenthal PD, Gaffikin L, Deganus S, Lewis R, Emerson M Cervical cancer prevention: safety, acceptability, and feasibility of a single-visit approach in Accra, Ghana. Am J Obstet Gynecol. 2007 ;196(4):407.

16. Chumworathayi B, Srisupundit S, Lumbiganon P, Limpaphayom KK. One-year follow-up of single-visit approach to cervical cancer prevention based on visual inspection with acetic acid wash and immediate cryotherapy in rural Thailand. Int J Gynecol Cancer. 2008; 18(4):736-42.

17. Bhatla N, Gulati A, Mathur SR, Rani S, Anand K, Muwonge $\mathrm{R}$ Evaluation of cervical screening in rural North India. Int $\mathrm{J}$ Gynecol Obstet. 2009;105 (2):145-9. 